\title{
Early Life Factors Associated with Preschool Wheezing in Preterm Infants
}

\author{
Ying-Lun Hsu ${ }^{1,+}$, Hsin-Chun Huang ${ }^{1,2,+}{ }^{+}$, Ting-Yu Su ${ }^{1}$ and I-Lun Chen ${ }^{1,2, *}$ \\ 1 Department of Pediatrics, Kaohsiung Chang Gung Memorial Hospital, Kaohsiung 833, Taiwan; \\ lun0831@hotmail.com (Y.-L.H.); hhuang@cgmh.org.tw (H.-C.H.); teneec8c8c8@hotmail.com (T.-Y.S.) \\ 2 School of Traditional Chinese Medicine, College of Medicine, Chang Gung University, Linkou 333, Taiwan \\ * Correspondence: memeo1013@hotmail.com \\ + These authors contributed equally to this work.
}

Citation: Hsu, Y.-L.; Huang, H.-C.; $\mathrm{Su}, \mathrm{T}$.-Y.; Chen, I.-L. Early Life Factors Associated with Preschool Wheezing in Preterm Infants. Children 2021, 8 , 732. https://doi.org/10.3390/ children8090732

Academic Editor: Bo Chawes

Received: 23 July 2021

Accepted: 25 August 2021

Published: 26 August 2021

Publisher's Note: MDPI stays neutral with regard to jurisdictional claims in published maps and institutional affiliations.

Copyright: () 2021 by the authors. Licensee MDPI, Basel, Switzerland. This article is an open access article distributed under the terms and conditions of the Creative Commons Attribution (CC BY) license (https:// creativecommons.org/licenses/by/ $4.0 /)$.

\begin{abstract}
Advanced neonatal care has increased the survival of neonates born prematurely, and prematurity is a well-known risk factor for asthma/wheezing disorders. Thus, this prospective study aimed to determine the early life factors associated with preschool wheezing in premature neonates. Preterm neonates born between 2012 and 2017 were recruited, excluding those with bacterial infection within 7 days of life, maternal sepsis, and maternal chorioamnionitis. Birth and admission history, comorbidities, and maternal history were documented. Respiratory problems were followed-up at the neonatal outpatient department. Patients were divided into wheezing and non-wheezing groups. Data were analyzed using the Mann-Whitney test and Fisher's exact test, and multivariable logistic regression was used to define the risk factors of preschool wheezing/asthma. A total of 125 preterm infants were enrolled, including 19 in the wheezing group and 106 in the non-wheezing group. Patients in the wheezing group had longer duration of intubation $(p=0.025)$, higher rates for exclusive breast milk feeding $(p=0.012)$, and higher re-hospitalization rates for respiratory tract infections $(p<0.001)$, especially for respiratory syncytial virus (RSV) bronchiolitis $(p=0.045)$. The incidence of allergic rhinitis was also higher in the wheezing group $(p=0.005)$. After multivariable logistic regression, allergic rhinitis and re-hospitalization for respiratory tract infections were two significant risk factors for preschool wheezing/asthma in premature neonates. Close follow-up of premature infants at high risk for asthma susceptibility is recommended.
\end{abstract}

Keywords: asthma; premature infants; risk

\section{Introduction}

Symptoms of wheezing occurring in children before age 3 years, even transient symptoms, are found to lead to a persistent reduction in lung function by age 6 years [1], and some of these children eventually develop asthma [2]. Recent advances in neonatal intensive care have greatly increased the survival rate of extremely preterm infants. The greater survival, in turn, leads to higher frequencies of lung consequences, especially among those with bronchopulmonary dysplasia (BPD), a major concern for the long-term care of premature infants. Preterm infants have higher rates of early and persistent wheezing compared with full-term infants [3,4].

Asthma affects about $15 \%$ of school-age children in Taiwan, and its prevalence among school-age children has been increasing in recent years with contributing factors such as air quality, especially $\mathrm{PM}_{2.5}$ [5], increasing parental atopy [6], and changed dietary pattern [7]. The pathophysiology of asthma in children born preterm may be different from that of full-term children. Lower gestational age (GA), lower birth body weight (BBW), and greater infant weight gain are presumed risk factors for asthma/wheezing in preterm births $[8,9]$. Preexisting genetic and environmental factors such as maternal infection, multiple pregnancy, tobacco use resulting in premature delivery, and immature lung development and immune system with susceptibility to recurrent pulmonary infections, 
as well as postnatal lung injuries from barotrauma of the ventilator and oxygen toxicity, all may contribute to impaired lung function in preterm infants [10,11]. Preterm neonates may be born by cesarean section [12], a known asthma risk factor, for multiple pregnancy, fetal distress, or maternal complications. Available evidence suggests that, compared to full-term births, preterm births put children at greater risk of developing respiratory diseases in later life, especially obstructive lung disease with impaired lung function, and as a result, a higher prevalence of asthma and chronic obstructive pulmonary disease $[10,11]$. Children born preterm are also shown to have a lower incidence of atopy, but without lower incidence of asthma, compared with children born at term [13].

During hospitalization, perinatal infection and nosocomial infection are common diseases in premature neonates that may help to protect children from asthma/wheezing. Early life infection can active Th1 cell responses and lead to the production of antiinflammatory cytokines [14]. However, early use of antibiotics is known for its association with the development of asthma [15]. Moreover, viral infection, especially respiratory syncytial virus (RSV), is an important risk factor for recurrent wheezing [16]. Thus, palivizumab, the monoclonal antibody, has been used since 2010 based on the Taiwan National Health Insurance (TNHI) policy for preventing severe RSV infection in the high-risk population. Previous study revealed the protective effect of palivizumab on the development of asthma in preterm infants [17]. However, evidence from a multicenter study showed that palivizumab prophylaxis administered to preterm infants lowered the incidence of recurrent wheezing but not that of atopic asthma [18]. This study aimed to analyze the risk factors for preschool wheezing in premature infants who needed respiratory support at birth and the effects of palivizumab.

\section{Materials and Methods}

\subsection{Patient Population}

Premature babies who were born at or less than GA 34 weeks between August 2012 and May 2017 were enrolled in this prospective observational study after obtaining signed informed consent from their parents or guardians. Besides the babies born at Chang Gung Memorial Hospital, those who were born elsewhere but admitted to the neonatal intensive care unit (NICU) at Chang Gung Memorial Hospital were also included. Only neonates who needed respiratory support after birth, including nasal continuous positive airway pressure, nasal intermittent mandatory ventilation, or mechanical ventilation, were included. A total of 186 preterm neonates were recruited initially. Neonates with bacterial infections within the first 7 days of life, maternal sepsis, or maternal clinical chorioamnionitis were excluded. Infants with bacterial infections were diagnosed by clinical symptoms and/or proven culture from biofluids, including blood, urine, or cerebral spinal fluid. Clinical chorioamnionitis was defined as maternal fever, uterine fundal tenderness, purulent or foul amniotic fluid, and bacterial growth in the amniotic fluid culture or placenta. Finally, a total of 125 neonates were included for analysis.

The birth and admission history of the included premature infants, including GA, BBW, APGAR score, duration of intubation, breast milk feeding, frequency of infectious episodes, and comorbidities such as BPD, significant patent ductus arteriosus (sPDA), respiratory distress syndrome (RDS), periventricular leukomalacia (PVL), intraventricular hemorrhage (IVH), retinopathy of prematurity (ROP), and necrotizing enterocolitis (NEC), were documented. Breast milk feeding was defined solely at discharge of the neonate. Information regarding maternal history, including maternal education, colonization of group B streptococcus (GBS), use of prenatal steroid or antibiotics, smoking history during pregnancy, and maternal disorders such as preeclampsia, fever, gestational diabetes (GDM), and premature rupture of membrane (PROM) were also recorded. BPD was defined as infants requiring more than $21 \%$ oxygen for 28 days after birth $[19,20]$. sPDA implies that the diameter of the PDA is larger than $2.5 \mathrm{~mm}$ [21]. 


\subsection{Patient Follow-Up}

The qualified patients were divided into wheezing $(n=19)$ and non-wheezing $(n=106)$ groups. The operational definition of wheezing included diagnosis by a pediatrician or was defined by the use of asthma medications, such as inhaled selective $\beta 2$ agonists and/or inhaled corticosteroids (ICS) for more than twice a year for at least 1 year and/or the use of oral leukotriene modifiers for more than 1 month. Neonatologists followed these patients at the outpatient department (OPD) and/or by phone interviews to determine their status, respiratory symptoms, medication history, and any ongoing or chronic illnesses. All patients were followed for at least 3 years. In addition, the documented frequency of wheezing and diagnosis at re-admissions were obtained from the patients' medical records. The usage of palivizumab in this study was according to the recommendation by the TNHI policy. Before April 2015, all premature infants younger than one year of age and born at or less than 28 weeks of gestation or born at or less than 35 weeks of gestation with BPD were indicated to receive prophylactic palivizumab $750 \mathrm{mg} / \mathrm{kg}$ intramuscularly every month for 6 doses. After April 2015, the indication of receiving palivizumab was extended to all premature infants younger than one year of age who were born at or less than 30 weeks of gestation. The first dose was administered within $3-5$ days before discharge.

\subsection{Statistical Analysis}

The Mann-Whitney test and Fisher's exact test were used to analyze continuous and categorical variables, respectively. Continuous variables with non-normal distribution are presented as medians, and categorical variables are presented as percentage (\%). The sample size was 126 , which was calculated with alpha $5 \%$ and power $80 \%$. Demographic information of mothers and neonates, the comorbidities of premature infants (BPD, RDS, sPDA, PVL, IVH, ROP, and NEC), the frequency of re-admission due to respiratory infection, RSV infection, use of palivizumab, and family and atopic history were compared between the wheezing and non-wheezing groups. Multivariable logistic regression by backward selection was used to compare the most significant risk factors in early life for preschool wheezing on children born prematurely. The effect size was measured by odds ratio with $95 \%$ confidence interval. Gestational age, birth weight, and significant variables in Table 1 were selected in multivariable models. Though not significant difference, gestational age and birth weight were known as major risk factors in asthma children who were born preterm. However, the effect of gender in asthma development was not reported specifically in premature infants [22]. Therefore, despite no significant difference, we included gestational age and birth weight but did not include gender. The level of significance was set at $p<0.05$. All statistical analyses were performed using IBM SPSS Statistics 25.0 software (IBM Corp. Armonk, NY, USA). 
Table 1. Baseline characteristics between wheezing and non-wheezing groups.

\begin{tabular}{|c|c|c|c|}
\hline & $\begin{array}{l}\text { Wheezing } \\
(n=19)\end{array}$ & $\begin{array}{l}\text { Non-Wheezing } \\
\quad(n=106)\end{array}$ & $p$-Value \\
\hline \multicolumn{4}{|l|}{ Birth history } \\
\hline Gestational age (wk) & $28.1(25.9-30.9)$ & $29.9(27.6-31.3)$ & 0.070 \\
\hline Birth weight $(\mathrm{g})$ & $1140(840-1460)$ & $1265(917.5-1572.5)$ & 0.407 \\
\hline Male/Female & $12 / 7$ & $54 / 52$ & 0.455 \\
\hline APGAR score at $1 \mathrm{~min}$ & $5(3-6)$ & $6(4.5-7)$ & 0.196 \\
\hline APGAR score at $5 \mathrm{~min}$ & $8(6-9)$ & $8(7-9)$ & 0.244 \\
\hline \multicolumn{4}{|l|}{ Maternal history } \\
\hline Mode of delivery $(\mathrm{C} / \mathrm{N})$ & $9 / 10$ & $40 / 66$ & 0.453 \\
\hline Prenatal steroid $(\%)$ & 84.2 & 74.0 & 0.561 \\
\hline Group B streptococcus (\%) & 0 & 4.0 & 1.000 \\
\hline Prenatal antibiotic $(\%)$ & 84.2 & 78.6 & 0.761 \\
\hline Smoking during pregnancy (\%) & 5.3 & 4.8 & 1.000 \\
\hline Preeclampsia $(\%)$ & 15.8 & 14.2 & 0.737 \\
\hline Maternal fever (\%) & 10.5 & 5.7 & 0.350 \\
\hline $\operatorname{PROM}(\%)$ & 36.8 & 43.4 & 0.626 \\
\hline Gestational diabetes (\%) & 5.3 & 3.8 & 0.568 \\
\hline College education (\%) & 35.3 & 46.5 & 0.440 \\
\hline \multicolumn{4}{|l|}{ Admission history } \\
\hline Intubation duration (day) & $41(0-76)$ & $3.5(0-10)$ & 0.025 \\
\hline Surfactant administration (\%) & 63.2 & 59.4 & 0.805 \\
\hline Infection frequency & $0(0-2)$ & $0(0-1)$ & 0.086 \\
\hline Exclusive breast milk feeding (\%) & 68.4 & 36.8 & 0.012 \\
\hline RDS grade & $2.0(1.0-2.5)$ & $2.0(1.0-2.5)$ & 0.699 \\
\hline Bronchopulmonary dysplasia (\%) & 84.2 & 72.6 & 0.397 \\
\hline Significant PDA $(\%)$ & 21.0 & 23.6 & 1.000 \\
\hline Peri-ventricular leukomalacia (\%) & 5.3 & 5.7 & 1.000 \\
\hline Intraventricular hemorrhage (\%) & 21.1 & 20.8 & 1.000 \\
\hline ROP $(\%)$ & 31.6 & 22.6 & 0.394 \\
\hline Necrotizing enterocolitis (\%) & 21.1 & 15.2 & 0.508 \\
\hline \multicolumn{4}{|l|}{ Follow-up history } \\
\hline Re-admission for res. infection & $3(1-5)$ & $0(0-1)$ & $<0.001$ \\
\hline RSV infection (\%) & 15.8 & 2.8 & 0.045 \\
\hline Use of Palivizumab (\%) & $68.4 \%$ & $55.7 \%$ & 0.327 \\
\hline \multicolumn{4}{|l|}{ Atopic History } \\
\hline Allergic rhinitis (\%) & 31.6 & 6.6 & 0.005 \\
\hline Atopic dermatitis (\%) & 10.5 & 3.8 & 0.226 \\
\hline Family atopic history (\%) & 15.8 & 17.0 & 1.000 \\
\hline
\end{tabular}

C/N: caesarean section/normal spontaneously delivery; PROM: premature rupture of membranes; RDS: respiratory distress syndrome; PDA: patent ductus arteriosus; res.: respiratory; RSV: respiratory syncytial virus. Continuous variables with non-normal distribution are presented as medians. Categorical variables are presented as percentage (\%). Significant difference is defined as $p<0.05$.

\section{Results}

A total of 186 preterm infants were recruited in this study initially. Eighteen neonates died during their first hospitalization. Thirty-six of the survivors were excluded due to maternal infections (maternal clinical chorioamnionitis $(n=33)$; maternal sepsis $(n=2)$, and cytomegalovirus $(n=1))$. Seven babies were excluded because of bacterial infections within the first 7 days of life, (GBS infection $(n=3)$, pneumonia $(n=2)$, and sepsis $(n=2))$. Finally, a total of 125 infants were included as the analytic sample in this study.

These 125 infants were divided into the wheezing $(n=19)$ and non-wheezing $(n=106)$ groups, based on our operational definition of wheezing. Table 1 shows the characteristics for the two groups. The median GA was 28.1 weeks and 29.9 weeks in the wheezing and non-wheezing groups, respectively. The median BBW was $1140 \mathrm{~g}$ and $1265 \mathrm{~g}$ in the wheezing and non-wheezing groups, respectively. Despite the lower GA and BBW noted 
in the wheezing group, no statistically significant differences were observed between the two groups. A longer intubation period was observed in the wheezing group than in the non-wheezing group $(p=0.025)$. No significant differences were observed in the common comorbidities of prematurity, including BPD, grade of RDS, frequency of infectious episodes, sPDA, PVL, IVH, ROP, and NEC, between the two groups. Although there was a higher exclusive breast-feeding rate in the wheezing group than in the non-wheezing group $(p=0.012)$, there was no significance after multivariable logistic regression (Table 2$)$.

Table 2. Multivariable logistic analysis of early life factors between wheezing and non-wheezing groups.

\begin{tabular}{|c|c|c|c|c|c|c|}
\hline & Model 1 & Model 2 & Model 3 & Model 4 & Model 5 & Model 6 \\
\hline Gestational age (wk) & $\begin{array}{c}0.98 \\
(0.57-1.68)\end{array}$ & & & & & \\
\hline Birth weight (g) & $\begin{array}{c}1.00 \\
(0.99-1.00)\end{array}$ & $\begin{array}{c}1.00 \\
(0.99-1.00)\end{array}$ & & & & \\
\hline Intubation duration (days) & $\begin{array}{c}1.01 \\
(0.97-1.05)\end{array}$ & $\begin{array}{c}1.01 \\
(0.97-1.04)\end{array}$ & $\begin{array}{c}1.01 \\
(0.97-1.04)\end{array}$ & $\begin{array}{c}1.00 \\
(0.97-1.04)\end{array}$ & & \\
\hline Exclusive BM feeding (\%) & $\begin{array}{c}0.47 \\
(0.11-2.04)\end{array}$ & $\begin{array}{c}0.46 \\
(0.11-1.95)\end{array}$ & $\begin{array}{c}0.48 \\
(0.12-1.96)\end{array}$ & $\begin{array}{c}0.48 \\
(0.12-1.97)\end{array}$ & $\begin{array}{c}0.47 \\
(0.12-1.91)\end{array}$ & \\
\hline $\begin{array}{l}\text { Re-admission for res. } \\
\text { infection }\end{array}$ & $\begin{array}{c}3.32 \\
(1.70-6.49)^{* * *}\end{array}$ & $\begin{array}{c}3.31 \\
(1.70-6.45) * * *\end{array}$ & $\begin{array}{c}3.40 \\
(1.82-6.37)^{* * *}\end{array}$ & $\begin{array}{c}3.43 \\
(1.84-6.40) * * *\end{array}$ & $\begin{array}{c}3.55 \\
(2.02-6.24) * * *\end{array}$ & $\begin{array}{c}3.62 \\
(2.01-6.34)^{* * *}\end{array}$ \\
\hline RSV infection (\%) & $\begin{array}{c}0.69 \\
(0.05-9.14)\end{array}$ & $\begin{array}{c}0.68 \\
(0.05-8.97)\end{array}$ & $\begin{array}{c}0.74 \\
(0.06-8.76)\end{array}$ & & & \\
\hline Allergic rhinitis (\%) & $\begin{array}{c}0.12 \\
(0.02-0.63) *\end{array}$ & $\begin{array}{c}0.12 \\
(0.02-0.63) *\end{array}$ & $\begin{array}{c}0.12 \\
(0.02-0.63) *\end{array}$ & $\begin{array}{c}0.12 \\
(0.02-0.63) *\end{array}$ & $\begin{array}{c}0.12 \\
(0.02-0.63) *\end{array}$ & $\begin{array}{c}0.13 \\
(0.02-0.65) *\end{array}$ \\
\hline
\end{tabular}

${ }^{*} p<0.05 ;{ }^{* * *} p<0.001 ; \mathrm{BM}$ : breast milk; RSV: respiratory syncytial virus. res.: respiratory. Model 1: multivariable logistic analysis with gestational age, birth weight, exclusive breast milk feeding, allergic rhinitis, intubation period, re-admission for respiratory infection, and RSV infection. Model 2: birth weight, exclusive breast milk feeding, allergic rhinitis, intubation period, re-admission for respiratory infection, and RSV infection were analyzed. Model 3: exclusive breast milk feeding, allergic rhinitis, intubation period, re-admission for respiratory infection, and RSV infection. Model 4: exclusive breast milk feeding, allergic rhinitis, intubation period, and re-admission for respiratory infection. Model 5: exclusive breast milk feeding, allergic rhinitis, and re-admission for respiratory infection. Model 6: allergic rhinitis and re-admission for respiratory infection. Data are presented with ORs and 95\% CI.

A significantly higher frequency of allergic rhinitis and re-hospitalization due to respiratory tract infections was found in the wheezing group than in the non-wheezing group $(p=0.005,<0.001)$. Additionally, patients with RSV infection history were also more likely to develop wheezing $(p=0.045)$. Six infants were diagnosed with laboratoryconfirmed RSV infection, and half of them developed recurrent episodes of wheezing later. After multivariable logistic regression, re-hospitalization due to respiratory tract infections and allergic rhinitis were the two most frequent factors associated with wheezing episodes (Table 2).

\section{Discussion}

The results of this study showed that longer intubation periods and higher frequency of respiratory tract infection, especially RSV infection, were associated with preschool wheezing development. Additionally, allergic rhinitis had a higher incidence in infants with recurrent wheezing. However, family atopic history and exclusive breast milk feeding seemed not to be associated with wheezing episodes in preterm infants. A previous study also revealed that wheezing phenotypes in preterm infants were associated with perinatal and postnatal events, not with atopic mechanisms [23].

RSV is the most common pathogen in infantile bronchiolitis, and many studies have demonstrated its link to the development of asthma/wheezing [24,25]. RSV bronchiolitis that is severe enough to warrant hospitalization increases the risk of wheezing, current asthma, and impaired lung function [26]. Preterm infants with and without BPD both easily developed coughing or wheezing in their first year of life [27]. Palivizumab prophylaxis is known to protect children against RSV infection by decreasing wheezing episodes and hospitalization rates in the first 2 years of life [28]. Palivizumab is an FDA-approved 
monoclonal antibody that is directed against the RSV fusion protein (F glycoprotein) and is recommended by the American Academy of Pediatrics as prophylaxis for high-risk infants younger than 1 year of age [29]. In Taiwan, RSV infections occur throughout the year and without significant seasonality [30]. Thus, the protocol we follow for palivizumab injection, which is based on the TNHI policy, is continuous six doses monthly starting from 3-5 days before discharge, whether during RSV season or not. The protocol is safe and effective for preventing RSV hospitalization in preterm infants [31].

In the present study, six infants had RSV infection. One of them did not receive palivizumab because it did not conform to the TNHI policy. Another infant had RSV infection during the palivizumab prophylaxis period. An additional four infants had RSV infection, but not within the palivizumab prophylaxis period. Three of these six patients had RSV infection and developed wheezing during their childhood. One had RSV infection before receiving palivizumab prophylaxis, and the other two developed the infection after completing six doses of palivizumab prophylaxis (Figure 1).

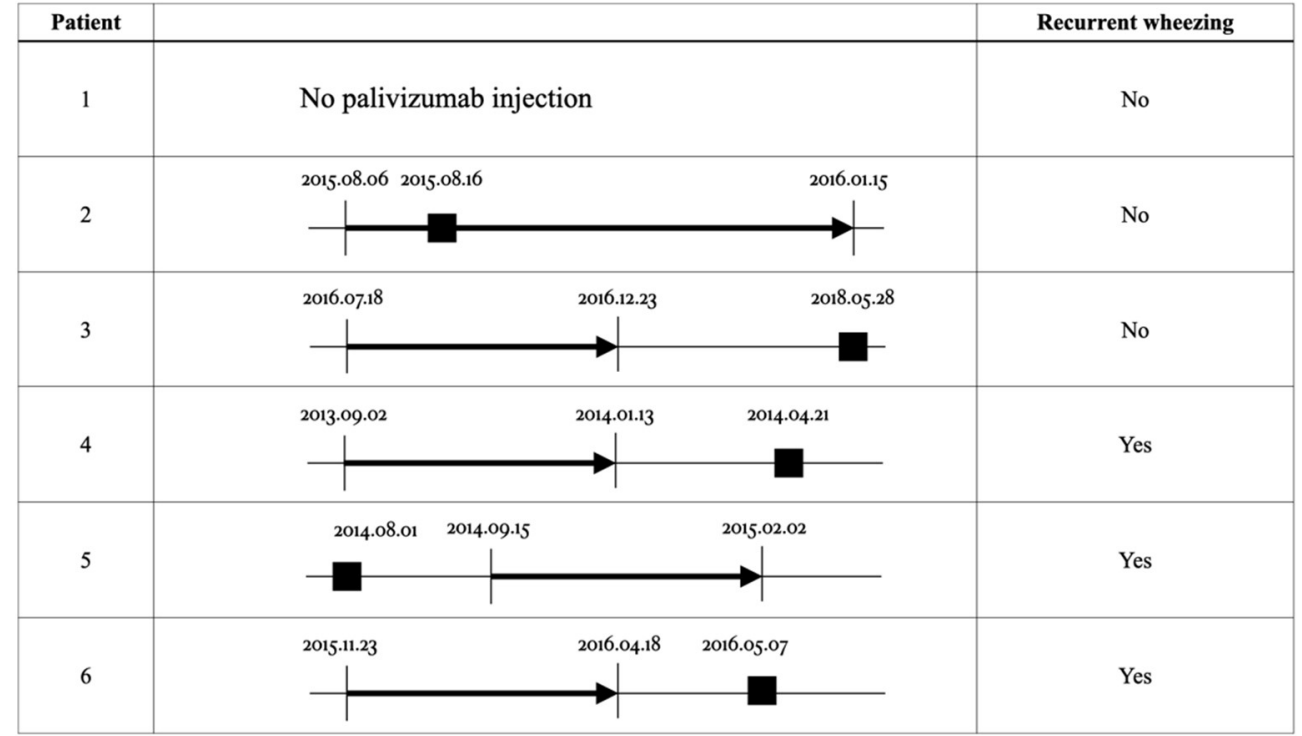

Figure 1. The course of palivizumab prophylaxis and time of RSV infection in six patients. Arrows $(\longrightarrow)$ mean the course of palivizumab prophylaxis. Black squares $(\square)$ mean RSV infection date. RSV: respiratory syncytial virus.

Regarding the atopic history of the patients and their families, results of the present study showed no significant difference between the two groups except for allergic rhinitis. The proportion of exclusive breast feeding was higher in the wheezing group than in the non-wheezing group, but without an observed effect on wheezing. A previous study revealed that the incidence of atopy was lower in children who were born preterm than in those born at full term according to the skin prick test, but the incidence of asthma did not decrease [13]. Another study showed that preterm birth was associated with an increased risk of severe asthma and a decreased risk of severe atopic dermatitis [32]. Therefore, the mechanism of asthma development in preterm births may be different from that in full-term infants. It is worth noting that the asthma group had significantly longer duration of intubation $(p<0.025)$. No previous study has demonstrated an association between mechanical ventilation and asthma/wheezing. The mechanism of asthma in premature infants may be explained by multiple factors, such as ventilator-induced injury to the immature lungs or recurrent virus infections. Genetic polymorphism of IL-8 may increase disease severity in infants with RSV infection [33], which may be a predisposing factor for the development of asthma after RSV bronchiolitis.

This study has several limitations that must be mentioned. First, the evaluation of asthma/wheezing disorder in preschool children is difficult due to the lack of objective 
lung function measurements and biomarkers. Diagnosis usually depends on therapeutic responses. Asthma/wheezing disorder was diagnosed by a pediatrician or was defined by the use of asthma medications twice a year [15]. The wheezing group in the present study did not have significantly lower gestational age and birth weight, compared to those of the non-wheezing group. Small sample size may contribute to these nonsignificant results. Another probable explanation for these known risk factors not reaching statistical significance may be related to the inclusion criteria for this study. Only premature infants born at or less than 34 weeks of gestation and who needed ventilator support were included, not all preterm neonates, which may have led to selection bias. Furthermore, environmental factors such as tobacco smoke, air pollution, molds and fungi, indoor chemicals, and household factors have an important impact on wheezing disorders [34,35]. Although all of our enrolled patients were living in southern Taiwan, large differences and variations in air pollution levels are found, which may influence the degree of wheezing and/or asthma susceptibility. Tobacco smokes of family members living together were not recorded. Household factors as pets, dust mites, and cockroaches are hard to evaluate.

Recurrent wheezing during preschool childhood is associated with poorer lung function and higher airway resistance [36,37], which suggests increased asthma susceptibility. In the present study, longer intubation periods, hospitalization for RSV bronchiolitis, and allergic rhinitis were associated with preschool wheezing. Knowledge of the correlation between early life factors and wheezing disorders may help to guide early intervention among high-risk infants, such as avoiding longer intubation at preterm birth and avoiding RSV infection. Extending the availability of RSV monoclonal antibody through palivizumab injection may be considered for these infants.

Author Contributions: Conceptualization, Y.-L.H.; Methodology, T.-Y.S.; Software, T.-Y.S.; Validation, H.-C.H.; Formal Analysis, I.-L.C.; Investigation, I.-L.C.; Resources, I.-L.C.; Data Curation, T.-Y.S. and Y.-L.H.; Writing-Original Draft Preparation, Y.-L.H.; Writing-Review \& Editing, I.-L.C. and H.-C.H.; Visualization, H.-C.H.; Supervision, I.-L.C. and H.-C.H.; Project Administration, I.-L.C. and H.-C.H.; Funding Acquisition, I.-L.C. and H.-C.H. All authors have read and agreed to the published version of the manuscript.

Funding: This research was funded by grant CMRPG8F0711, CMRPG8G0991from Kaohsiung Chang Gung Memorial Hospital.

Institutional Review Board Statement: The study was conducted according to the guidelines of the Declaration of Helsinki, and approved by the Institutional Review Board of Chang Gung Memorial Hospital. Approval number: 201201131A3D001, start date: 1 July 2012, and 201600730A3C501, start date: 4 August 2016.

Informed Consent Statement: Informed consent was obtained from all subjects involved in the study.

Data Availability Statement: The data presented in this study are available on request from the corresponding author. The availability of the data is restricted to investigators based in academic institutions.

Acknowledgments: We appreciated our colleagues from the Stem Cell Research Core Laboratory whose insight and expertise greatly assisted our research, and the Biostatistics Center, Kaohsiung Chang Gung Memorial Hospital, for the statistical work.

Conflicts of Interest: The authors declare no conflict of interest.

\section{References}

1. Martinez, F.D.; Wright, A.L.; Taussig, L.M.; Holberg, C.J.; Halonen, M.; Morgan, W.J. Asthma and wheezing in the first six years of life. The Group Health Medical Associates. N. Engl. J. Med. 1995, 332, 133-138. [CrossRef] [PubMed]

2. Padem, N.; Glick Robison, R. The infant and toddler with wheezing. Allergy Asthma Proc. 2019, 40, 393-395. [CrossRef] [PubMed]

3. Kotecha, S.J.; Watkins, W.J.; Lowe, J.; Granell, R.; Henderson, A.J.; Kotecha, S. Comparison of the associations of early-life factors on wheezing phenotypes in preterm-born children and term-born children. Am. J. Epidemiol. 2019, 188, 527-536. [CrossRef] [PubMed] 
4. Been, J.V.; Lugtenberg, M.J.; Smets, E.; van Schayck, C.P.; Kramer, B.W.; Mommers, M.; Sheikh, A. Preterm birth and childhood wheezing disorders: A systematic review and meta-analysis. PLoS Med. 2014, 11, e1001596. [CrossRef]

5. Chen, B.Y.; Chen, C.H.; Chuang, Y.C.; Wu, Y.H.; Pan, S.C.; Guo, Y.L. Changes in the relationship between childhood asthma and ambient air pollution in Taiwan: Results from a nationwide survey repeated 5 years apart. Pediatr. Allergy Immunol. 2019, 30, 188-194. [CrossRef]

6. Barnish, M.S.; Tagiyeva, N.; Devereux, G.; Aucott, L.; Turner, S. Changes in the relationship between asthma and associated risk factors over fifty years. Pediatr. Allergy Immunol. 2017, 28, 162-169. [CrossRef]

7. Lee, S.C.; Yang, Y.H.; Chuang, S.Y.; Liu, S.C.; Yang, H.C.; Pan, W.H. Risk of asthma associated with energy-dense but nutrient-poor dietary pattern in Taiwanese children. Asia Pac. J. Clin. Nutr. 2012, 21, 73-81.

8. Sonnenschein-van der Voort, A.M.; Arends, L.R.; de Jongste, J.C.; Annesi-Maesano, I.; Arshad, S.H.; Barros, H.; Basterrechea, M.; Bisgaard, H.; Chatzi, L.; Corpeleijn, E.; et al. Preterm birth, infant weight gain, and childhood asthma risk: A meta-analysis of 147,000 European children. J. Allergy Clin. Immunol. 2014, 133, 1317-1329. [CrossRef]

9. Simoes, M.; Inoue, Y.; Matsunaga, N.Y.; Carvalho, M.R.V.; Ribeiro, G.L.T.; Morais, E.O.; Ribeiro, M.; Morcillo, A.M.; Ribeiro, J.D.; Toro, A. Recurrent wheezing in preterm infants: Prevalence and risk factors. J. Pediatr. 2019, 95, 720-727. [CrossRef]

10. Hwang, J.S.; Rehan, V.K. Recent advances in bronchopulmonary dysplasia: Pathophysiology, prevention, and treatment. Lung 2018, 196, 129-138. [CrossRef]

11. Thunqvist, P.; Tufvesson, E.; Bjermer, L.; Winberg, A.; Fellman, V.; Domellof, M.; Melen, E.; Norman, M.; Hallberg, J. Lung function after extremely preterm birth-A population-based cohort study (EXPRESS). Pediatr. Pulmonol. 2018, 53, 64-72. [CrossRef]

12. Goedicke-Fritz, S.; Härtel, C.; Krasteva-Christ, G.; Kopp, M.V.; Meyer, S.; Zemlin, M. Preterm Birth Affects the Risk of Developing Immune-Mediated Diseases. Front. Immunol. 2017, 8, 1266. [CrossRef] [PubMed]

13. Siltanen, M.; Wehkalampi, K.; Hovi, P.; Eriksson, J.G.; Strang-Karlsson, S.; Jarvenpaa, A.L.; Andersson, S.; Kajantie, E. Preterm birth reduces the incidence of atopy in adulthood. J. Allergy Clin. Immunol. 2011, 127, 935-942. [CrossRef] [PubMed]

14. Noutsios, G.T.; Floros, J. Childhood asthma: Causes, risks, and protective factors; a role of innate immunity. Swiss Med. Wkly. 2014, 144, w14036. [CrossRef] [PubMed]

15. Chen, I.L.; Huang, H.C.; Chang, Y.H.; Huang, H.Y.; Yeh, W.J.; Wu, T.Y.; Suen, J.L.; Yang, S.N.; Hung, C.H. Effect of antibiotic use for acute bronchiolitis on new-onset asthma in children. Sci. Rep. 2018, 8, 6090. [CrossRef]

16. Jackson, D.J. Early-life viral infections and the development of asthma: A target for asthma prevention? Curr. Opin. Allergy Clin. Immunol. 2014, 14, 131-136. [CrossRef] [PubMed]

17. Igde, M.; Kabasakal, H.; Ozturk, O.; Karatekin, G.; Aygun, C. Palivizumab prophylaxis, respiratory syncytial virus and subsequent development of asthma. Minerva Pediatr. 2018, 70, 252-259. [CrossRef]

18. Mochizuki, H.; Kusuda, S.; Okada, K.; Yoshihara, S.; Furuya, H.; Simoes, E.A.F. Scientific Committee for Elucidation of Infantile Asthma. Palivizumab prophylaxis in preterm infants and subsequent recurrent wheezing. Six-year follow-up study. Am. J. Respir. Crit. Care Med. 2017, 196, 29-38. [CrossRef]

19. Jobe, A.H.; Bancalari, E. Bronchopulmonary dysplasia. Am. J. Respir. Crit. Care Med. 2001, 163, 1723-1729. [CrossRef]

20. Day, C.L.; Ryan, R.M. Bronchopulmonary dysplasia: New becomes old again! Pediatr. Res. 2017, 81, 210-213. [CrossRef]

21. Cambier, P.A.; Kirby, W.C.; Wortham, D.C.; Moore, J.W. Percutaneous closure of the small (less than $2.5 \mathrm{~mm}$ ) patent ductus arteriosus using coil embolization. Am. J. Cardiol. 1992, 69, 815-816. [CrossRef]

22. Pérez-Yarza, E.G.; Moreno-Galdó, A.; Ramilo, O.; Rubí, T.; Escribano, A.; Torres, A.; Sardón, O.; Oliva, C.; Pérez, G.; Cortell, I.; et al. Risk factors for bronchiolitis, recurrent wheezing, and related hospitalization in preterm infants during the first year of life. Pediatr. Allergy Immunol. 2015, 26, 797-804. [CrossRef]

23. Unal, S.; Kaya, A.; Bilgin, L.; Misirlioglu, E.; Kocabas, C.N. Wheezing, asthma, and atopy in premature infants at 2 years of age. Turk. J. Med. Sci. 2017, 47, 607-613. [CrossRef]

24. Korsten, K.; Blanken, M.O.; Buiteman, B.J.M.; Nibbelke, E.E.; Naaktgeboren, C.A.; Bont, L.J.; Wildenbeest, J.G. RSV hospitalization in infancy increases the risk of current wheeze at age 6 in late preterm born children without atopic predisposition. Eur. J. Pediatr. 2019, 178, 455-462. [CrossRef]

25. Sigurs, N.; Aljassim, F.; Kjellman, B.; Robinson, P.D.; Sigurbergsson, F.; Bjarnason, R.; Gustafsson, P.M. Asthma and allergy patterns over 18 years after severe RSV bronchiolitis in the first year of life. Thorax 2010, 65, 1045-1052. [CrossRef] [PubMed]

26. Zomer-Kooijker, K.; van der Ent, C.K.; Ermers, M.J.; Uiterwaal, C.S.; Rovers, M.M.; Bont, L.J.; RSV Corticosteroid Study Group. Increased risk of wheeze and decreased lung function after respiratory syncytial virus infection. PLoS ONE 2014, 9, e87162. [CrossRef] [PubMed]

27. Pramana, I.A.; Latzin, P.; Schlapbach, L.J.; Hafen, G.; Kuehni, C.E.; Nelle, M.; Riedel, T.; Frey, U. Respiratory symptoms in preterm infants: Burden of disease in the first year of life. Eur. J. Med. Res. 2011, 16, 223-230. [CrossRef] [PubMed]

28. Prais, D.; Kaplan, E.; Klinger, G.; Mussaffi, H.; Mei-Zahav, M.; Bar-Yishay, E.; Stafler, P.; Steuer, G.; Sirota, L.; Blau, H. Short- and long-term pulmonary outcome of palivizumab in children born extremely prematurely. Chest 2016, 149, 801-808. [CrossRef] [PubMed]

29. Committee on Infectious Diseases. From the American Academy of Pediatrics: Policy statements-Modified recommendations for use of palivizumab for prevention of respiratory syncytial virus infections. Pediatrics 2009, 124, 1694-1701. [CrossRef] [PubMed]

30. Tsai, H.P.; Kuo, P.H.; Liu, C.C.; Wang, J.R. Respiratory viral infections among pediatric inpatients and outpatients in Taiwan from 1997 to 1999. J. Clin. Microbiol. 2001, 39, 111-118. [CrossRef] 
31. Chi, H.; Hsu, C.H.; Chang, J.H.; Chiu, N.C.; Hung, H.Y.; Kao, H.A.; Weng, L.C.; Huang, F.Y.; Chiu, Y.Y.; Chang, L.Y.; et al. A novel six consecutive monthly doses of palivizumab prophylaxis protocol for the prevention of respiratory syncytial virus infection in high-risk preterm infants in Taiwan. PLoS ONE 2014, 9, e100981. [CrossRef]

32. Tronnes, H.; Wilcox, A.J.; Lie, R.T.; Markestad, T.; Moster, D. The association of preterm birth with severe asthma and atopic dermatitis: A national cohort study. Pediatr. Allergy Immunol. 2013, 24, 782-787. [CrossRef]

33. Hull, J.; Thomson, A.; Kwiatkowski, D. Association of respiratory syncytial virus bronchiolitis with the interleukin 8 gene region in UK families. Thorax 2000, 55, 1023-1027. [CrossRef]

34. Castro-Rodriguez, J.A.; Forno, E.; Rodriguez-Martinez, C.E.; Celedon, J.C. Risk and protective factors for childhood asthma: What is the evidence? J. Allergy Clin. Immunol. Pract. 2016, 4, 1111-1122. [CrossRef]

35. Freeman, N.C.; Schneider, D.; McGarvey, P. Household exposure factors, asthma, and school absenteeism in a predominantly Hispanic community. J. Expo. Anal. Environ. Epidemiol. 2003, 13, 169-176. [CrossRef] [PubMed]

36. Lowe, L.A.; Simpson, A.; Woodcock, A.; Morris, J.; Murray, C.S.; Custovic, A.; NAC Manchester Asthma and Allergy Study Group. Wheeze phenotypes and lung function in preschool children. Am. J. Respir. Crit. Care Med. 2005, 171, 231-237. [CrossRef] [PubMed]

37. Brussee, J.E.; Smit, H.A.; Koopman, L.P.; Wijga, A.H.; Kerkhof, M.; Corver, K.; Vos, A.P.; Gerritsen, J.; Grobbee, D.E.; Brunekreef, B.; et al. Interrupter resistance and wheezing phenotypes at 4 years of age. Am. J. Respir. Crit. Care Med. 2004, 169, $209-213$. [CrossRef] 